\title{
A Note on the Fixed Point of Generalized Eventual Cyclic Gross Contractive Mappings
}

\author{
Jin Liang and Sheng-Hua Yan \\ Department of Mathematics, Shanghai Jiao Tong University, Shanghai 200240, China \\ Correspondence should be addressed to Jin Liang; jinliang@sjtu.edu.cn \\ Received 5 August 2013; Accepted 7 September 2013 \\ Academic Editor: T. Diagana
}

Copyright (C) 2013 J. Liang and S.-H. Yan. This is an open access article distributed under the Creative Commons Attribution License, which permits unrestricted use, distribution, and reproduction in any medium, provided the original work is properly cited.

Based on the work of Agarwal et al., in press, we introduce a concept of generalized eventual cyclic gross contractive mapping in metric spaces, which is a generalization of the eventual cyclic gross contractions. Furthermore, we analyze the existence of a fixed point for this type of contractive mapping, and present a new and general fixed point theorem.

\section{Introduction}

The following classical Banach contraction principle is wellknown.

Theorem 1. If $T$ is a self-mapping in a complete metric space $X$ satisfying the following condition:

$$
d(T x, T y)<\lambda d(x, y), \quad \lambda \in[0,1),
$$

then $T$ has a unique fixed point.

Based on this principle and the idea of its proof, many researchers have presented numerous extensions of the principle and new types of fixed point theorems (cf, e.g., [1-3]).

In [3], Karpagam and Agrawal proved the following unique fixed point for cyclic mappings.

Theorem 2 (see [3]). Let $A$ and $B$ be two nonempty closed subsets of a complete metric space $(X, d)$. Suppose $\phi: A \cup B \rightarrow$ $A \cup B$ is a cyclic mapping such that for some $x \in A$, there exists $a k_{x} \in(0,1)$ such that

$$
d\left(\phi^{2 n} x, \phi y\right) \leq k_{x} d\left(\phi^{2 n-1} x, y\right), \quad n \in N, \quad y \in A .
$$

Then, $A \cap B$ is nonempty and $\phi$ has a unique fixed point in $A \cap B$.
Very recently, Agarwal et al. [1] defined a new type of cyclic mappings, "eventual cyclic gross contraction" in complete metric spaces, and established a fixed point theorem for the eventual cyclic gross contraction.

Theorem 3 (see [1]). Let $A$ and $B$ be two nonempty closed subsets of a complete metric space $(X, d)$, and let $T: A \cup B \rightarrow$ $A \cup B$ be an eventual cyclic gross contraction. Then $A \cap B$ is nonempty and $T$ has a unique fixed point in $A \cap B$.

Inspired by the work in [1], in this paper, we introduce a concept of generalized eventual cyclic gross contractive mapping in metric spaces, which is a generalization of the eventual cyclic gross contractions. Furthermore, we obtain a fixed point theorem for this type of contractive mappings, which extends Theorem 3.

\section{Generalized Eventual Cyclic Gross Contractive Mappings}

Let $R^{+}$be the set of all nonnegative real numbers and $N$ the set of all natural numbers. Let $(X, d)$ be a metric space, and let $A$ and $B$ be nonempty subsets of $X$.

Now, we introduce the concept of generalized eventual cyclic gross contractive mappings. 
Definition 4. A mapping $T: A \cup B \rightarrow A \cup B$ is called a generalized eventual cyclic gross contractive mapping if the following are satisfied:

(1) $T(A) \subset B, T(B) \subset A$,

(2) for some $x \in A$,

$$
\begin{gathered}
f\left(d\left(T^{2 n} x, T y\right)\right) \\
\leq f\left(\lambda d\left(T^{2 n-1} x, T y\right)+(1-\lambda) d\left(T^{2 n} x, y\right)\right) \\
-g\left(d\left(T^{2 n-1} x, T y\right), d\left(T^{2 n} x, y\right)\right), \\
n \geq n_{0} \in N, y \in A,
\end{gathered}
$$

where $\lambda \in[0,1), f: R^{+} \rightarrow R^{+}$is a monotone increasing and continuous function, $g: R^{+} \times R^{+} \rightarrow R^{+}$is a lower semicontinuous mapping such that $g(a, b)=0$ if and only if $a=b=0$, and $n_{0}$ is sufficiently large.

Lemma 5. Let $T$ be a generalized eventual cyclic gross contractive mapping and $\lambda \in(1 / 2,1]$. Then $\left\{T^{n} x\right\}$ is a Cauchy sequence for every $x \in A \cup B$.

Proof. For every $x \in A \cup B$, let

$$
n \geq n_{0}, \quad y=T^{2 n-2} x .
$$

Then, (3) and the monotone increasing property of $f$ imply that

$$
\begin{aligned}
d\left(T^{2 n} x, T^{2 n-1} x\right) \leq & (1-\lambda) d\left(T^{2 n} x, T^{2 n-2} x\right) \\
\leq & (1-\lambda) d\left(T^{2 n} x, T^{2 n-1} x\right) \\
& +(1-\lambda) d\left(T^{2 n-1} x, T^{2 n-2} x\right),
\end{aligned}
$$

since

$$
\begin{aligned}
f( & \left.\left(T^{2 n} x, T y\right)\right) \\
= & f\left(d\left(T^{2 n} x, T^{2 n-1} x\right)\right) \\
\leq & f\left(\lambda d\left(T^{2 n-1} x, T^{2 n-1} x\right)+(1-\lambda) d\left(T^{2 n} x, T^{2 n-2} x\right)\right) \\
& -g\left(d\left(T^{2 n-1} x, T^{2 n-1} x\right), d\left(T^{2 n} x, T^{2 n-2} x\right)\right) \\
= & f\left((1-\lambda) d\left(T^{2 n} x, T^{2 n-2} x\right)\right)-g\left(0, d\left(T^{2 n} x, T^{2 n-2} x\right)\right) \\
\leq & f\left((1-\lambda) d\left(T^{2 n} x, T^{2 n-2} x\right)\right) .
\end{aligned}
$$

Hence,

$$
d\left(T^{2 n} x, T^{2 n-1} x\right) \leq \frac{1-\lambda}{\lambda} d\left(T^{2 n-1} x, T^{2 n-2} x\right) .
$$

Thus,

$$
d\left(T^{n} x, T^{n+1} x\right) \leq \frac{1-\lambda}{\lambda} d\left(T^{n-1} x, T^{n} x\right) .
$$

Since $\lambda \in(1 / 2,1]$, we deduce that $\lim _{n \rightarrow \infty} d\left(T^{n} x, T^{n+1} x\right)$ exists. Set

$$
\lim _{n \rightarrow \infty} d\left(T^{n} x, T^{n+1} x\right)=l \geq 0 .
$$

If $l>0$, then (5) implies that

$$
l \leq(1-\lambda) \lim _{n \rightarrow \infty} d\left(T^{2 n} x, T^{2 n-2} x\right) \leq 2(1-\lambda) l .
$$

So, we have

$$
1-\lambda \geq \frac{1}{2} .
$$

This is impossible since $\lambda \leq 1 / 2$. Therefore,

$$
\lim _{n \rightarrow \infty} d\left(T^{n} x, T^{n+1} x\right)=0 .
$$

This means that, for any $\varepsilon>0$, there exists a natural number $N_{1}$ such that for any natural number $n \geq N_{1}$,

$$
d\left(T^{n} x, T^{n+1} x\right)<\varepsilon .
$$

Moreover, for any natural number $m>n>0$, we have

$$
\begin{aligned}
d\left(T^{n+N_{1}} x, T^{m+N_{1}} x\right) & \leq \sum_{i=n}^{m-1} d\left(T^{N_{1}+i} x, T^{N_{1}+i+1} x\right) \\
& \leq \sum_{i=n}^{m-1}\left(\frac{1-\lambda}{\lambda}\right)^{i} d\left(T^{N_{1}} x, T^{N_{1}+1} x\right) \\
& <\frac{((1-\lambda) / \lambda)^{n}}{1-((1-\lambda) / \lambda)} \varepsilon .
\end{aligned}
$$

This implies that

$$
d\left(T^{n+N_{1}} x, T^{m+N_{1}} x\right) \longrightarrow 0
$$

as $n \rightarrow \infty$, since

$$
\frac{1-\lambda}{\lambda} \in[0,1) .
$$

Therefore, $\left\{T^{n} x\right\}$ is a Cauchy sequence.

Lemma 6. Let $T$ be a generalized eventual cyclic gross contractive mapping and $\lambda \in[0,1 / 2]$. Then $\left\{T^{n} x\right\}$ is a Cauchy sequence for every $x \in A \cup B$.

Proof. For every $x \in \mathrm{A} \cup B$, let

$$
n \geq n_{0}, \quad y=T^{2 n} x .
$$

Then,

$$
\begin{aligned}
d\left(T^{2 n} x, T^{2 n+1} x\right) & \leq \lambda d\left(T^{2 n-1} x, T^{2 n+1} x\right) \\
& \leq \lambda d\left(T^{2 n-1} x, T^{2 n} x\right)+\lambda d\left(T^{2 n} x, T^{2 n+1} x\right)
\end{aligned}
$$


since

$$
\begin{aligned}
f( & \left.d\left(T^{2 n} x, T y\right)\right) \\
= & f\left(d\left(T^{2 n} x, T^{2 n+1} x\right)\right) \\
\leq & f\left(\lambda d\left(T^{2 n-1} x, T^{2 n+1} x\right)+(1-\lambda) d\left(T^{2 n} x, T^{2 n} x\right)\right) \\
& -g\left(d\left(T^{2 n-1} x, T^{2 n+1} x\right), d\left(T^{2 n} x, T^{2 n} x\right)\right) \\
= & f\left(\lambda d\left(T^{2 n-1} x, T^{2 n+1} x\right)\right)-g\left(d\left(T^{2 n-1} x, T^{2 n} x\right), 0\right) \\
\leq & f\left(\lambda d\left(T^{2 n-1} x, T^{2 n+1} x\right)\right) .
\end{aligned}
$$

So,

$$
d\left(T^{2 n} x, T^{2 n+1} x\right) \leq \frac{\lambda}{1-\lambda} d\left(T^{2 n-1} x, T^{2 n} x\right)
$$

Hence,

$$
d\left(T^{n} x, T^{n+1} x\right) \leq \frac{\lambda}{1-\lambda} d\left(T^{n-1} x, T^{n} x\right)
$$

Since $\lambda \in[0,1 / 2]$, we see that for all $n \geq n_{0}$, the nonnegative sequence $\left\{d\left(T^{n} x, T^{n+1} x\right)\right\}$ is decreasing. Let

$$
\lim _{n \rightarrow \infty} d\left(T^{n} x, T^{n+1} x\right)=l \geq 0
$$

Then we obtain

$$
l \leq \lambda \lim _{n \rightarrow \infty} d\left(T^{2 n-1} x, T^{2 n+1} x\right) \leq 2 \lambda l .
$$

This implies that

$$
\lambda \geq \frac{1}{2}
$$

if $l \neq 0$. Clearly, $\lambda>1 / 2$ is impossible. Moreover, $\lambda=1 / 2$ is also impossible by the proof of [1, Theorem 2.4].

Now, we show that $\left\{T^{n} x\right\}$ is a Cauchy sequence. It follows from

$$
\lim _{n \rightarrow \infty} d\left(T^{n} x, T^{n+1} x\right)=0
$$

that for any $\varepsilon>0$, there exists a natural number $N_{0}$ such that for any natural number $n \geq N_{0}$,

$$
d\left(T^{n} x, T^{n+1} x\right)<\varepsilon
$$

For $\lambda \in[0,1 / 2)$ and any natural number $m>n>0$, we have

$$
\begin{aligned}
d\left(T^{n+N_{0}} x, T^{m+N_{0}} x\right) & \leq \sum_{i=n}^{m-1} d\left(T^{N_{0}+i} x, T^{N_{0}+i+1} x\right) \\
& \leq \sum_{i=n}^{m-1}\left(\frac{\lambda}{1-\lambda}\right)^{i} d\left(T^{N_{0}} x, T^{N_{0}+1} x\right) \\
& <\frac{(\lambda /(1-\lambda))^{n}}{1-(\lambda /(1-\lambda))} \varepsilon
\end{aligned}
$$

So

$$
d\left(T^{n+N_{0}} x, T^{m+N_{0}} x\right) \longrightarrow 0
$$

as $n \rightarrow \infty$, since

$$
\frac{\lambda}{1-\lambda} \in[0,1)
$$

Therefore, $\left\{T^{n} x\right\}$ is a Cauchy sequence.

For $\lambda=1 / 2$, by the proof of [1, Theorem 2.4], we know that $\left\{T^{n} x\right\}$ also is a Cauchy sequence.

The following is our central theorem about cycle mapping in complete metric spaces.

Theorem 7. Assume that $(X, d)$ is a complete metric space, $A$ and $B$ are closed, and $T$ is a generalized eventual cyclic gross contractive mapping. Then, $A \cap B$ is nonempty and $T$ has $a$ unique fixed point in $A \cap B$.

Proof. By the virtue of Lemmas 5 and 6, we know that for every $x \in A \cup B,\left\{T^{n} x\right\}$ is a Cauchy sequence. Since $(X, d)$ is a complete metric space, $A$ and $B$ are closed, there exists some $x_{0} \in A \cup B$ such that

$$
\lim _{n \rightarrow \infty} T^{n} x=x_{0}
$$

Therefore,

$$
\begin{gathered}
x_{0}=\lim _{n \rightarrow \infty} T^{2 n+1} x \in A, \\
x_{0}=\lim _{n \rightarrow \infty} T^{2 n} x \in B .
\end{gathered}
$$

So, $x_{0} \in A \cap B$; that is, $A \cap B \neq \emptyset$.

On the other hand, we obtain

$$
\begin{aligned}
f\left(d\left(T x_{0}, x_{0}\right)\right) \leq & f\left(\lambda d\left(x_{0}, x_{0}\right)+(1-\lambda) d\left(T x_{0}, x_{0}\right)\right) \\
& -g\left(d\left(x_{0}, x_{0}\right), d\left(T x_{0}, x_{0}\right)\right) \\
= & f\left((1-\lambda) d\left(x_{0}, T x_{0}\right)\right)-g\left(0, d\left(T x_{0}, x_{0}\right)\right),
\end{aligned}
$$

in view of

$$
\begin{aligned}
& f\left(d\left(T x_{0}, T^{2 n} x\right)\right) \\
& \leq f\left(\lambda d\left(x_{0}, T^{2 n} x\right)+(1-\lambda) d\left(T x_{0}, T^{2 n-1} x\right)\right) \\
& \quad-g\left(d\left(x_{0}, T^{2 n} x\right), d\left(T x_{0}, T^{2 n-1} x\right)\right) .
\end{aligned}
$$

If $d\left(T x_{0}, x_{0}\right)=0$, then $x_{0}$ is a fixed point of $T$. Otherwise, if $d\left(T x_{0}, x_{0}\right)>0$, then we have

$$
g\left(0, d\left(T x_{0}, x_{0}\right)\right)>0 \text {. }
$$

Equation (32) implies that

$$
f\left(d\left(T x_{0}, x_{0}\right)\right)<f\left((1-\lambda) d\left(x_{0}, T x_{0}\right)\right) .
$$


Hence,

$$
d\left(T x_{0}, x_{0}\right)<(1-\lambda)\left(d\left(x_{0}, T x_{0}\right)\right)
$$

This is impossible since $1-\lambda \in[0,1]$.

According to previous discussions, it is concluded that

$$
d\left(T x_{0}, x_{0}\right)=0
$$

and therefore, $x_{0}$ is a fixed point of $T$.

If there is $y_{0} \in A \cap B$ such that $T y_{0}=y_{0}$, then $d\left(x_{0}, y_{0}\right)=$ 0 ; that is, the fixed point of $T$ is unique, since

$$
g\left(d\left(x_{0}, y_{0}\right), d\left(x_{0}, y_{0}\right)\right) \leq 0
$$

in view of

$$
\begin{aligned}
f( & \left.d\left(x_{0}, y_{0}\right)\right) \\
= & f\left(d\left(T x_{0}, T y_{0}\right)\right) \\
\leq & f\left(\lambda d\left(x_{0}, T y_{0}\right)+(1-\lambda) d\left(T x_{0}, y_{0}\right)\right) \\
& -g\left(d\left(x_{0}, T y_{0}\right), d\left(T x_{0}, y_{0}\right)\right) \\
\leq & f\left(d\left(x_{0}, y_{0}\right)\right)-g\left(d\left(x_{0}, y_{0}\right), d\left(x_{0}, y_{0}\right)\right) .
\end{aligned}
$$

The proof is completed.

\section{Conflict of Interests}

The authors declare that there is no conflict of interests regarding the publication of this paper.

\section{Acknowledgment}

This work was supported by the NSF of China (11171210).

\section{References}

[1] R. P. Agarwal, J. Liang, and J. Zhang, "A fixed point theorem for cyclic mappings in complete metric spaces," Journal of Nonlinear and Convex Analysis. In press.

[2] M. Jleli and B. Samet, "Best proximity points for $\alpha-\psi$-proximal contractive type mappings and applications," Bulletin des Sciences Mathématiques. In press.

[3] S. Karpagam and S. Agrawal, "Best proximity point theorems for cyclic orbital MeirKeeler contraction maps," Nonlinear Analysis: Theory, Methods and Applications, vol. 74, no. 4, pp. 10401046, 2011. 


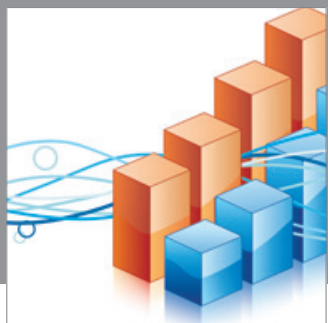

Advances in

Operations Research

mansans

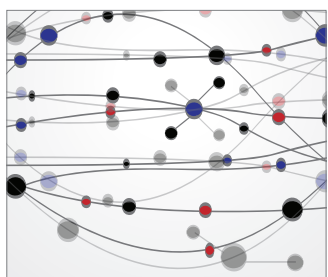

The Scientific World Journal
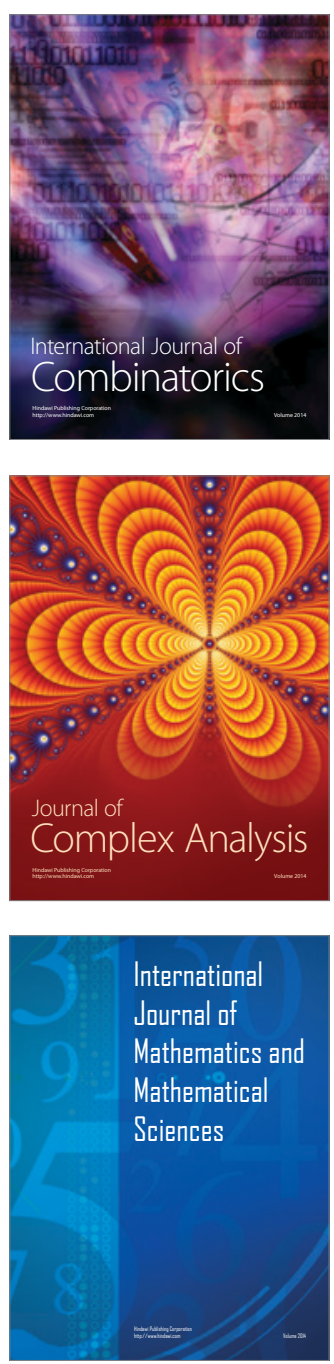
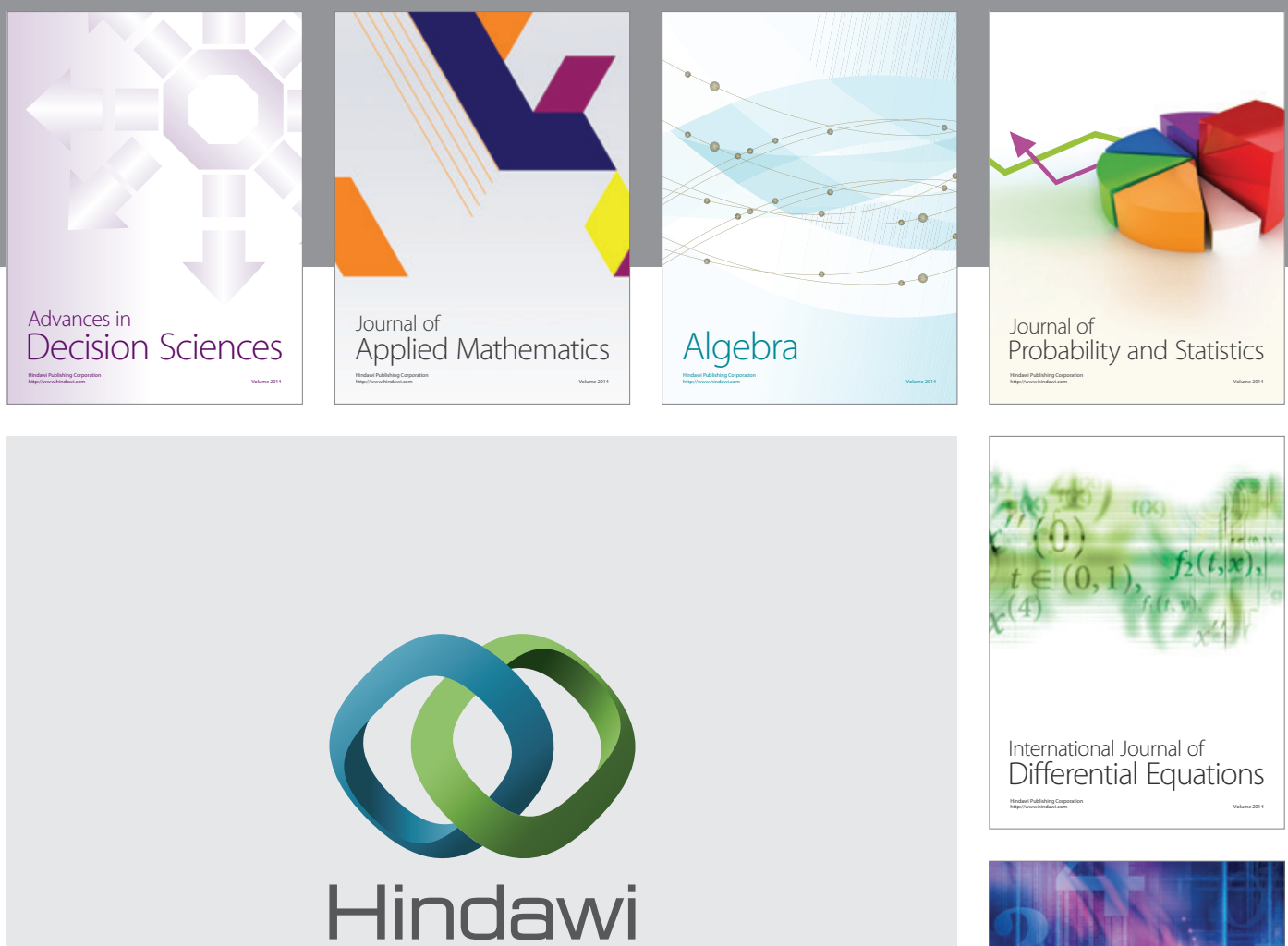

Submit your manuscripts at http://www.hindawi.com
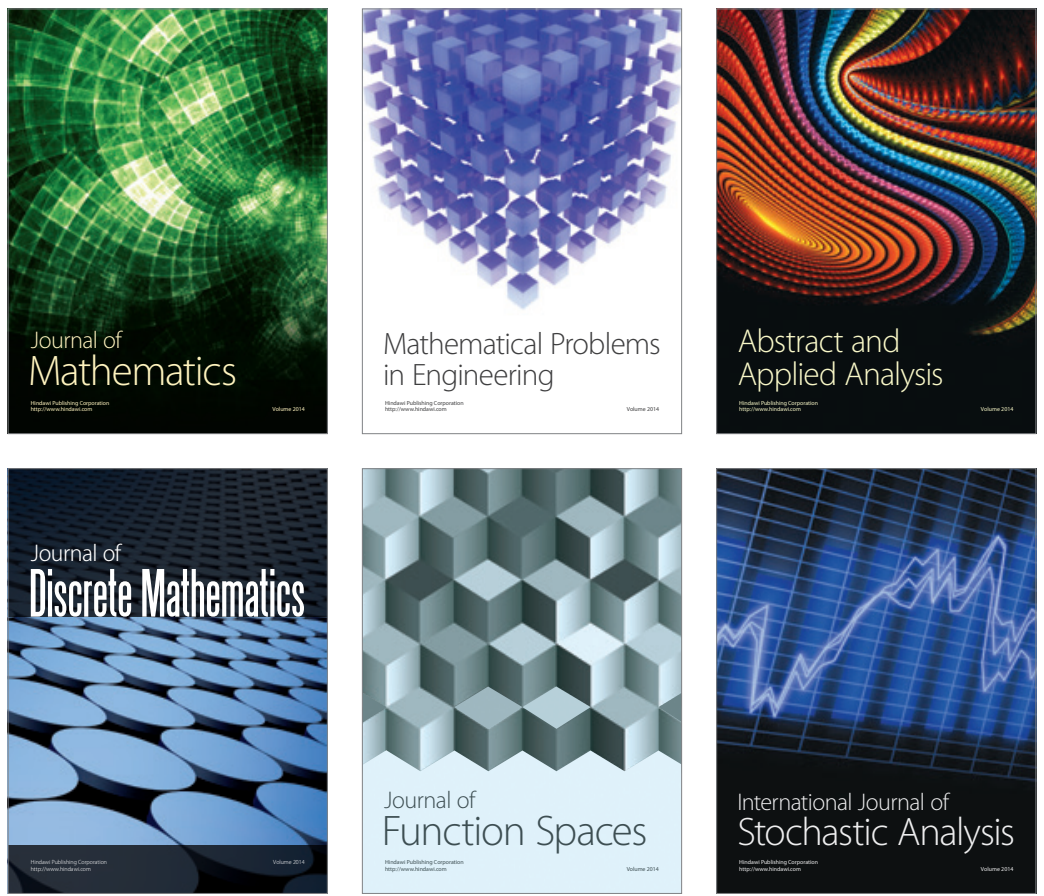

Journal of

Function Spaces

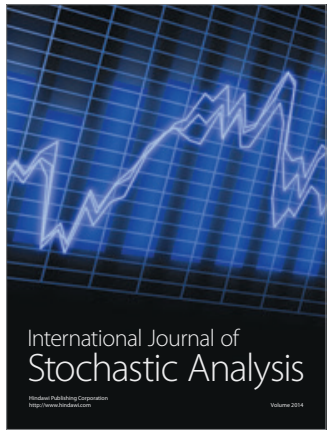

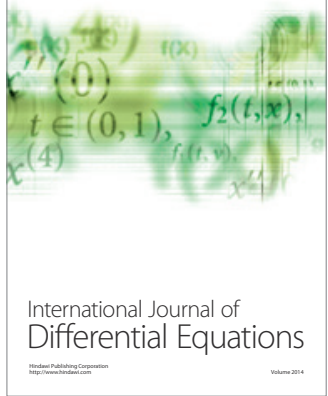
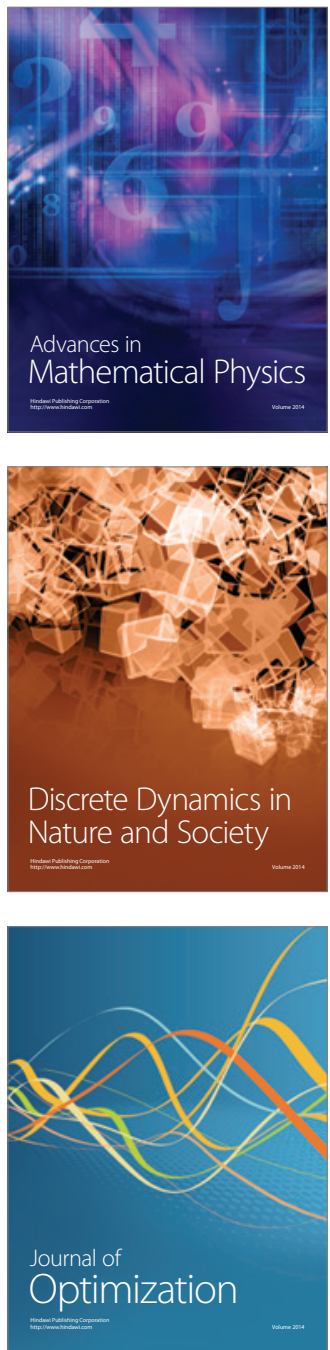